\title{
Cervical artificial disc replacement versus fusion in the cervical spine: a systematic review comparing long-term follow-up results from two FDA trials
}

Authors Praveen V Mummaneni ${ }^{1}$, Beejal Y Amin ${ }^{1}$, Jau-Ching Wu ${ }^{2}$, Erika D Brodt ${ }^{3}$, Joseph R Dettori ${ }^{3}$, Rick C Sasso ${ }^{4}$

Institutions $\quad{ }^{1}$ Department of Neurological Surgery, University of California-San Francisco, CA, USA

${ }^{2}$ Department of Neurosurgery, Neurological Institute, Taipei Veterans General Hospital, Beitou,

Taipei, Taiwan

${ }^{3}$ Spectrum Research Inc, Tacoma, WA, USA

${ }^{4}$ Indiana Spine Group, Indianapolis, IN, USA

\section{ABSTRACT}

Study design: Systematic review.

Clinical question: Does single-level unconstrained, semiconstrained, or fully constrained cervical artificial disc replacement (C-ADR) improve health outcomes compared with single-level anterior cervical discectomy and fusion (ACDF) in the long-term?

Methods: A systematic review was undertaken for articles published up to October 2011. Electronic databases and reference lists of key articles were searched to identify US Food and Drug Administration (FDA) studies reporting long-term ( $\geq 48$ months) follow-up results of C-ADR compared with ACDF. Non-FDA trials and FDA trials reporting outcomes at short-term or mid-term follow-up periods were excluded. Two independent reviewers assessed the strength of evidence using the GRADE criteria and disagreements were resolved by consensus.

Results: Two FDA trials reporting outcomes following C-ADR (Bryan disc, Prestige disc) versus ACDF at follow-up periods of 48 months and 60 months were found (follow-up rates are 68.7\% [318/463] and $50.1 \%$ [271/541], respectively). Patients in the C-ADR group showed a higher rate of overall success, greater improvements in Neck Disability Index, neck and arm pain scores, and SF-36 PhysicalComponent Scores at long-term follow-up compared with those in the ACDF group. The rate of adjacent segment disease was less in the C-ADR group versus the ACDF group at 60 months (2.9\% vs $4.9 \%)$. Normal segmental motion was maintained in the C-ADR group. Furthermore, rates of revision and supplemental fixation surgical procedures were lower in the arthroplasty group.

Conclusions: C-ADR is a viable treatment option for cervical herniated disc/spondylosis with radiculopathy resulting in improved clinical outcomes, maintenance of normal segmental motion, and low rates of subsequent surgical procedures at 4 to 5 years follow-up. More studies with long-term follow-up are warranted. 


\section{STUDY RATIONALE AND CONTEXT}

Several prospective, randomized, controlled clinical trials regarding cervical artificial disc replacement (C-ADR) have been published. However, the number of C-ADR patients with long-term follow-up for more than 4 years is still sparse. The purpose of this systematic review is to provide a summary of the available literature reporting long-term follow-up of C-ADR and to elucidate whether the favorable outcomes seen in the short-term continue after 4 to 5 years.

\section{CLINICAL QUESTION}

Does single-level unconstrained, semiconstrained, or fully constrained C-ADR improve health outcomes compared with single-level ACDF in the long-term?

Fig 1 Results of literature search.

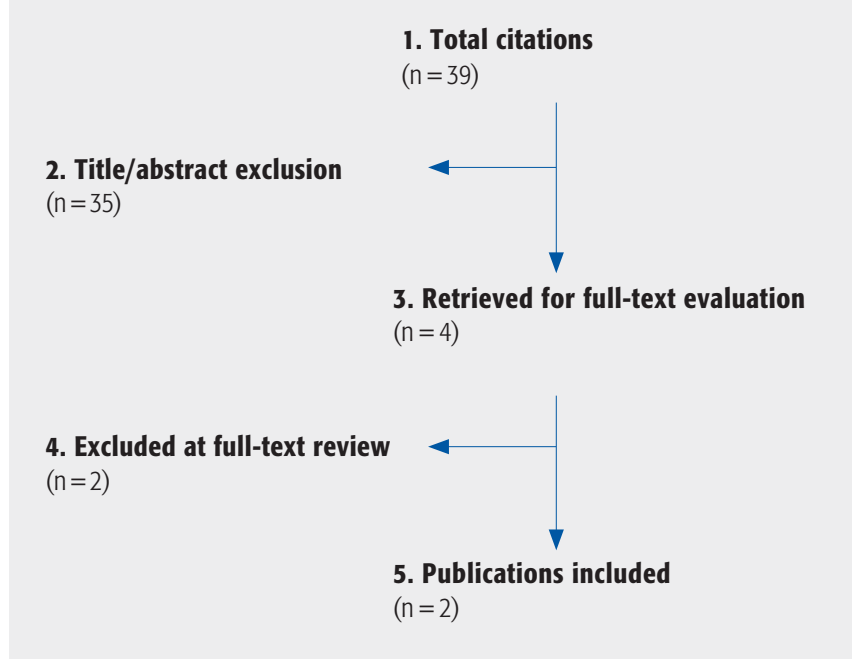

\section{MATERIALS AND METHODS}

Study design: Systematic review.

\section{Sampling:}

- Search: PubMed, Cochrane collaboration database, and National Guideline Clearinghouse databases; bibliographies of key articles.

- Dates searched: October 1, 2000, through October $1,2011$.

Inclusion criteria: (1) FDA trials comparing C-ADR with anterior cervical discectomy and fusion (ACDF); (2) follow-up $\geq 4$ years.

Exclusion criteria: (1) Non-FDA trials comparing CADR with ACDF; (2) follow-up $<4$ years.

Outcomes: Neck Disability Index (NDI), pain in the neck and arm (Visual Analog Scale [VAS]), Quality of Life (SF-36 Physical Component Score [PCS]), adjacent segment disease (ASD), neurological success, subsequent surgeries, and complications.

Analysis: Descriptive statistics.

Details about methods can be found in the Web Appendix at $w w w$.aospine.org/ebsj 


\section{RESULTS}

Two randomized, multicenter FDA trials comparing outcomes following C-ADR and ACDF with follow-up $>48$ months were found (Fig $\mathbf{1}$ ). Inclusion and exclusion criteria and demographic information for each study are listed in Table 1. Overall, a total of 1004 adult patients ( $47 \%$ male) with a mean age of 44 years were included. All patients were diagnosed with single-level degenerative disc disease between $\mathrm{C} 3$ and $\mathrm{C} 7$ and had failed a minimum of 6 weeks conservative treatment.

\section{Function, pain, and health-related quality of life (Table 2)}

- At 48 months in the Bryan trial, patients in the C-ADR group showed significantly greater mean improvement in NDI, VAS neck and arm pain, and SF-36 PCS measured at 48 months compared with patients in the ACDF group.

- At 60 months in the Prestige trial, only mean improvement in NDI scores was significantly greater in the C-ADR group (38.4 vs 34.1, $P=.022$ ); however, for the remaining three outcomes, mean improvements were slighter greater following C-ADR versus fusion.

\section{Success, ASD, and return to work (Table 3)}

At 48 months in the Bryan trial, overall success and NDI success, were achieved in a significantly greater proportion of C-ADR patients compared with ACDF patients $(P=.004$ and .003, respectively).

At both 48 months in the Bryan trial and 60 months in the Prestige trial, more patients achieved overall neurological success (maintenance or improvement) and were working following C-ADR compared with ACDF, although these differences were not significant.

The rate of ASD at 48 months in the Bryan trial was identical between groups $(4.1 \%)$; at 60 months in the Prestige trial the rate was $2.9 \%$ in the C-ADR group versus $4.9 \%$ in the ACDF group, however these differences were not statistically significant.

\section{Range of motion}

- Both studies reported preserved segmental range of motion in the cervical spine following C-ADR compared with ACDF: $8.5^{\circ}$ versus $1.1^{\circ}$ (48 months, Bryan) and $6.5^{\circ}$ versus $0.4^{\circ}$ (60 months, Prestige).

\section{Subsequent operations (Table 4)}

- No significant differences between groups were reported for rates of revisions, hardware removal, supplemental fixation, use of bone growth stimulators, or reoperation at 48 months postoperatively in the Bryan trial.

- At 60 months, a significant difference was seen between the Prestige C-ADR and ACDF groups, respectively, in revisions ( $0 \%$ vs $1.9 \% ; P=.028$ ), supplemental fixation ( $0 \%$ vs $1.9 \% ; P=.028)$, and the use of external bone growth stimulator ( $0 \%$ vs $2.6 \% ; P=.007)$.

\section{Adverse events}

- The Bryan study only reported more severe WHO grade 3 or 4 events that occurred after 24 months and up to 48 months follow-up in the C-ADR and ACDF groups, respectively: any, $24.3 \%$ vs $26.1 \%$; severe arm and neck pain, $1.7 \%$ vs $3.6 \%$; and new neurological deficits, $0 \%$ vs $1.4 \%$.

- In patients with complete radiographic follow-up at 60 months in the Prestige trial, subsidence (loss of $>$ than $2 \mathrm{~mm}$ in functional spinal unit height) was seen in $2.8 \%$ and $1.4 \%$ of patients in the C-ADR and ACDF groups, respectively; bridging bone was reported in $3.2 \%$ of the C-ADR patients.

\section{Clinical guidelines}

One guideline was found, published by the North American Spine Society (NASS) in 2010, entitled "Diagnosis and treatment of cervical radiculopathy from degenerative disorders." Among the major recommendations listed were the following statements relevant to the topic of this review:

- "ACDF and total disc arthroplasty (TDA) are suggested as comparable treatments, resulting in similarly successful short term outcomes, for single level degenerative cervical radiculopathy." (grade: B; fair evidence-level II or III studies)

- "Surgery is an option for the treatment of single level degenerative cervical radiculopathy to produce and maintain favourable long term (> 4 years) outcomes." (grade C; poor quality evidence-level IV or V studies) 
Table 1 Inclusion and exclusion criteria and demographics for the two included FDA trials providing long-term follow-up data.*

\begin{tabular}{|c|c|c|}
\hline & Inclusion & Exclusion \\
\hline $\begin{array}{l}\text { Burkus et al [1] (2010) } \\
\text { Prestige C-ADR } \\
\mathrm{N}=541 \\
\text { Male: } 46 \% \\
\text { Mean age: } 43.6(22-73) \text { y } \\
\text { C-ADR: } n=276 \\
\text { Male: } 46.4 \% \\
\text { Mean age: } 43.3(25-72) \text { y } \\
\text { Fusion: } n=265 \\
\text { Male: } 46.0 \% \\
\text { Mean age: } 43.9(22-73) \text { y }\end{array}$ & $\begin{array}{l}\text { - Adults }>18 \text { years of age } \\
\text { - Single-level symptomatic DDD between C3-7 } \\
\text { - Intractable radiculopathy, myelopathy or both } \\
\text { - NDI scores } \geq 30 \\
\text { - VAS neck pain scores } \geq 20 \\
\text { - Preserved motion at the symptomatic level found in all } \\
\text { included patients } \\
\text { - Unresponsive to } \geq 6 \text { weeks conservative treatment or } \\
\text { progressive neurological worsening despite conservative } \\
\text { treatment } \\
\text { - No previous procedures at the operative level } \\
\text { - Negative for several radiographic findings, medications, } \\
\text { and diagnoses }\end{array}$ & $\begin{array}{l}\text { - Multilevel symptomatic DDD or evidence of cervical instability } \\
\text { - Sagittal plane translation of }>3.5 \mathrm{~mm} \text { or sagittal plane angulation of }>20^{\circ} \text { at } \\
\text { a single level } \\
\text { - Symptomatic C2-C3 or C7-T1 disc disease } \\
\text { - Previous surgery at the involved level } \\
\text { - Severe facet joint disease at the involved level } \\
\text { - History of discitis } \\
\text { - Osteoporosis } \\
\text { - Metastases } \\
\text { - Medical condition that required long-term use of medication, such as steroid } \\
\text { or nonsteroidal antiinflammatory drugs that could affect bone quality and } \\
\text { fusion rates }\end{array}$ \\
\hline $\begin{array}{l}\text { Sasso et al [2] (2011) } \\
\text { Bryan C-ADR } \\
\mathrm{N}=463 \\
\text { Male: } 48 \% \\
\text { Mean age: } 44.5(25-78) \text { y } \\
\text { C-ADR: } n=242 \\
\text { Male: } 45.5 \% \\
\text { Mean age: } 44.4(25-78) \text { y } \\
\text { Fusion: } n=221 \\
\text { Male: } 51.1 \% \\
\text { Mean age: } 44.7(27-68) \text { y }\end{array}$ & $\begin{array}{l}\text { - DDD at single level between } \mathrm{C} 3 \text { and } \mathrm{C} 7 \\
\text { - Disc herniation with radiculopathy, spondylotic } \\
\text { radiculopathy, disc herniation with myelopathy, or } \\
\text { spondylotic myelopathy } \\
\text { - } 6 \text { weeks minimum unsuccessful conservative unless } \\
\text { myelopathy requiring immediate treatment } \\
\text { - CT, myelography and CT, and/or MRI demonstration of } \\
\text { need for surgical treatment } \\
\text { - } \geq 21 \text { years old } \\
\text { - Preoperative } \mathrm{NDI} \geq 30 \text { and minimum one clinical sign } \\
\text { associated with level to be treated } \\
\text { - Willing to sign informed consent and comply with protocol }\end{array}$ & $\begin{array}{l}\text { - Significant cervical anatomical deformity } \\
\text { - Moderate to advanced spondylosis } \\
\text { - Any combination of bridging osteophytes, marked reduction, or absence of } \\
\text { motion } \\
\text { - Collapse of intervertebral disc space of }>50 \% \text { normal height, radiographic } \\
\text { signs of subluxation }>3.5 \mathrm{~mm} \text {, angulation of disc space }>11^{\circ} \text { greater than } \\
\text { adjacent segments, significant kyphotic deformity or reversal or lordosis } \\
\text { - Axial neck pain as solitary symptom } \\
\text { - Previous cervical spine surgery } \\
\text { - Metabolic bone disease } \\
\text { - Active systemic infection or infection at operative site } \\
\text { - Known allergy to components of titanium, polyurethane, ethylene oxide } \\
\text { residuals } \\
\text { - Concomitant conditions requiring steroid treatment } \\
\text { - Daily insulin management } \\
\text { - Extreme obesity } \\
\text { - Medical condition which may interfere with postoperative management } \\
\text { program or may result in death before study completion } \\
\text { - Pregnancy } \\
\text { - Current or recent alcohol and/or drug abuser } \\
\text { - Signs of being geographically unstable }\end{array}$ \\
\hline
\end{tabular}

* FDA indicates US Food and Drug Administration; DDD, degenerative disc disease; NDI, Neck Disability Index; VAS, Visual Analog Scale; CT, computed tomography; and MRI, magnetic resonance scan. 
Table 2 Function, pain, and health-related quality of life outcomes following C-ADR versus fusion from two FDA trials with follow-up of 48 months or more.*

\begin{tabular}{|c|c|c|c|c|c|c|}
\hline & & & & \multicolumn{3}{|c|}{ Mean difference in scores from preop to follow-up } \\
\hline & & \multicolumn{2}{|c|}{ Mean preop score } & \multicolumn{2}{|l|}{$60 \mathrm{mo}$} & \multirow[b]{2}{*}{$P^{\dagger}$} \\
\hline & & $\begin{array}{l}\text { C-ADR } \\
(n=276)\end{array}$ & $\begin{array}{l}\text { Fusion } \\
(n=265)\end{array}$ & $\begin{array}{l}\text { C-ADR } \\
(n=144)\end{array}$ & $\begin{array}{l}\text { Fusion } \\
(n=127)\end{array}$ & \\
\hline \multirow{6}{*}{$\begin{array}{l}\text { Burkus et al [1] (2010) } \\
(\mathrm{N}=541)\end{array}$} & NDI & 55.7 & 56.4 & 38.4 & 34.1 & .022 \\
\hline & Neck pain & 68.2 & 69.3 & 56.0 & 52.4 & NS \\
\hline & Arm pain & 59.1 & 62.4 & 52.5 & 47.7 & NS \\
\hline & SF-36 PCS & 31.9 & 32.0 & 14.7 & 12.9 & NS \\
\hline & & \multicolumn{2}{|c|}{ Mean preop score } & \multicolumn{2}{|l|}{$48 \mathrm{mo}$} & \\
\hline & & $\begin{array}{l}\text { C-ADR } \\
(n=242)\end{array}$ & $\begin{array}{l}\text { Fusion } \\
(n=221)\end{array}$ & $\begin{array}{l}\text { C-ADR } \\
(n=181)\end{array}$ & $\begin{array}{l}\text { Fusion } \\
(\mathrm{n}=138)\end{array}$ & $P^{\dagger}$ \\
\hline \multirow{4}{*}{$\begin{array}{l}\text { Sasso et al [2] (2011) } \\
(\mathrm{N}=463)\end{array}$} & $\mathrm{NDI}$ & $51.4 \pm 15.3$ & $50.2 \pm 15.9$ & $39.0 \pm 19.1$ & $31.2 \pm 21.3$ & $<.001$ \\
\hline & Neck pain & $75.4 \pm 19.9$ & $74.8 \pm 23.0$ & $54.0 \pm 29.3$ & $44.7 \pm 33.6$ & .001 \\
\hline & Arm pain & $71.2 \pm 19.5$ & $71.2 \pm 25.1$ & $55.5 \pm 27.5$ & $50.3 \pm 35.9$ & .028 \\
\hline & SF-36 PCS & $32.6 \pm 6.7$ & $31.8 \pm 7.2$ & $15.7 \pm 11.1$ & $13.1 \pm 12.0$ & .007 \\
\hline
\end{tabular}

* C-ADR indicates cervical artificial disc replacement; FDA, US Food and Drug Administration; NDI, Neck Disability Index; SF-36, Short-Form 36

Questionnaire; and PCS, Physical Component Score.

$\dagger P$ values compare the mean improvement in scores from baseline to each follow-up time-point between C-ADR and fusion.

Table 3 Success, return to work, and ASD rate following C-ADR versus fusion from two FDA trials with follow-up of 48 months or more.*

\begin{tabular}{|c|c|c|c|c|c|c|}
\hline & \multicolumn{3}{|c|}{ Burkus et al [1] (2010), $60 \mathrm{mo}$} & \multicolumn{3}{|c|}{ Sasso et al [2] (2011), $48 \mathrm{mo}$} \\
\hline & C-ADR & Fusion & $P$ & C-ADR & Fusion & $P$ \\
\hline Overall success ${ }^{\dagger}$ & - & - & & $85.1 \%(154 / 181)$ & $72.5 \%(100 / 138)$ & .004 \\
\hline NDI success ${ }^{\ddagger}$ & - & - & & $90.6 \%(164 / 181)$ & $79.0 \%(109 / 138)$ & .003 \\
\hline Neurological success ${ }^{\S}$ & $95.0 \%(137 / 144)$ & $88.9 \%(113 / 127)$ & NS & $92.8 \%(167 / 180)$ & $89.9 \%(124 / 138)$ & NS \\
\hline ASD rate & $2.9 \%(8 / 276)$ & $4.9 \%(13 / 265)$ & NS & $4.1 \%(10 / 242)$ & $4.1 \%(9 / 221)$ & NS \\
\hline Working & $76.3 \%(110 / 144)$ & $72.6 \%(92 / 127)$ & NS & $74.7 \%(135 / 181)$ & $67.9 \%(123 / 181)$ & NS \\
\hline
\end{tabular}

* ASD indicates adjacent segment disease; C-ADR, cervical artificial disc replacement; FDA, US Food and Drug Administration; NDI, Neck Disability Index; and NS, not statistically significant.

$\dagger$ Composite measure in which patients had to achieve all the following: an improvement of $\geq 15$ points on NDI, neurological improvement, no serious

(WHO grade 3 or 4) adverse events related to the implant or surgical implantation procedure, and no subsequent surgery or intervention that would

be classified as treatment failure.

‡ Improvement of $\geq 15$ points in NDI from baseline.

$\S$ Defined as maintenance or improvement of all three neurological parameters (motor and sensory function, and reflexes).

Table 4 Subsequent operations following C-ADR versus fusion from two FDA trials with follow-up of 48 months or more.*

\begin{tabular}{|c|c|c|c|c|c|c|}
\hline & \multicolumn{3}{|c|}{ Burkus et al [1] (2010), $60 \mathrm{mo}$} & \multicolumn{3}{|c|}{ Sasso et al [2] (2011), $48 \mathrm{mo}$} \\
\hline & $\begin{array}{l}\text { C-ADR } \\
(n=276)\end{array}$ & $\begin{array}{l}\text { Fusion } \\
(n=265)\end{array}$ & $P$ & $\begin{array}{l}\text { C-ADR } \\
(n=242)\end{array}$ & $\begin{array}{l}\text { Fusion } \\
(n=221)\end{array}$ & $P$ \\
\hline Revisions & $0 \%(0)$ & $1.9 \%(5)$ & .028 & $0.4 \%(1)$ & $0 \%(0)$ & NS \\
\hline Hardware removal & $2.5 \%(7)$ & $4.9 \%(13)$ & NS & $1.7 \%(4)$ & $1.8 \%(4)$ & NS \\
\hline Supplemental fixation & $0 \%(0)$ & $1.9 \%(5)$ & .028 & $0 \%(0)$ & $2.3 \%(5)$ & NS \\
\hline External bone growth stimulator & $0 \%(0)$ & $2.6 \%(7)$ & .007 & $0 \%(0)$ & $0.9 \%(2)$ & NS \\
\hline Reoperation & $1.4 \%(4)$ & $0.8 \%(2)$ & NS & $1.7 \%(4)$ & $0.5 \%(1)$ & NS \\
\hline
\end{tabular}

* C-ADR indicates cervical artificial disc replacement; FDA, US Food and Drug Administration; and NS, not statistically significant. 


\section{CASE STUDY}

A 43-year-old woman presented with cervical myeloradiculopathy that did not respond to medical treatment for 6 weeks. The magnetic resonance images demonstrated a large herniated disc at the level of $\mathrm{C} 5 / 6$, eccentric to the right side (Fig 2). She then underwent cervical C-ADR at C5/6. Her symptoms improved significantly after surgery and x-rays taken 2 years postoperatively demonstrated very good range of motion at the index level (Fig 3). Her VAS arm pain score improved from a preoperative score of 8 to a postoperative score of 1 at 2 -year follow-up.
Fig 2 Preoperative axial (A) and sagittal (B) magnetic resonance images of a 43-year-old woman with myeloradiculopathy due to a C5/6 disc herniation.

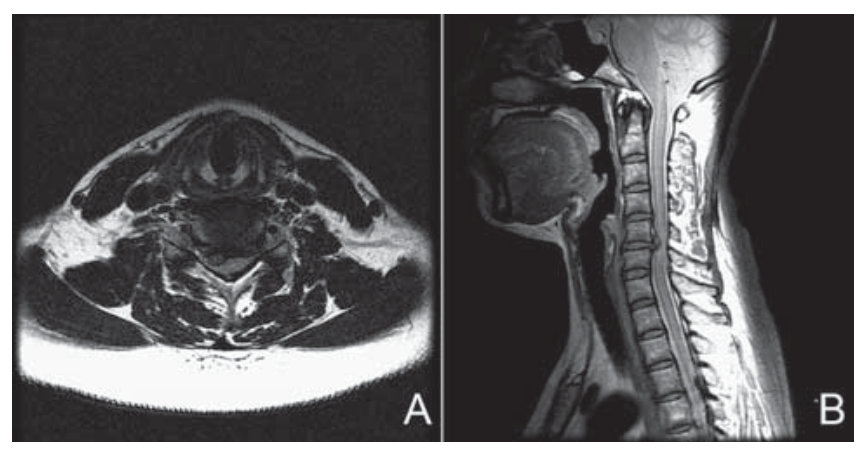

\section{DISCUSSION (Table 5)}

- Strengths: The question was reviewed systematically.

- Limitations: A small number of studies with longterm data comparing C-ADR with cervical ACDF were available.

- In both prospective studies, the C-ADR cohort maintained statistical improvement in validated clinical outcome measurements at 48 and 60 months and preserved segmental motion at the operated level.

- Rates of revision and supplemental fixation surgeries were lower in the C-ADR group.

- These studies demonstrate the durability of the C-ADR procedure; however, it may still be too early to detect implant-related failures. Future studies should examine issues such as wear-related failures, device fatigue, or delayed spinal instability.

- The loss to follow-up in the two studies analyzed increased over time. The follow-up rates were $68.7 \%$ (318/463) in the Bryan Disc study at 4 years and $50.1 \%$ $(271 / 541)$ in the Prestige ST study at 5 years. These high rates of lost to follow-up may alter the study results if those patients lost to follow-up had late-onset clinical or radiographic issues.

Fig 3 Postoperative flexion (A) and extension (B) $x$-rays of the patient 24 months after surgery. Her VAS arm pain score improved from 8 preoperatively to 1 postoperatively.

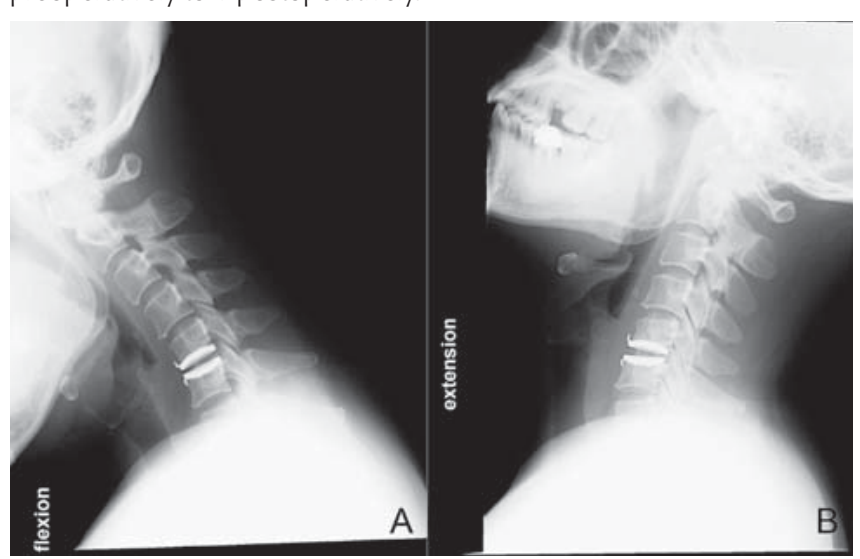




\section{EVIDENCE SUMMARY}

Table 5 Pain and disability.

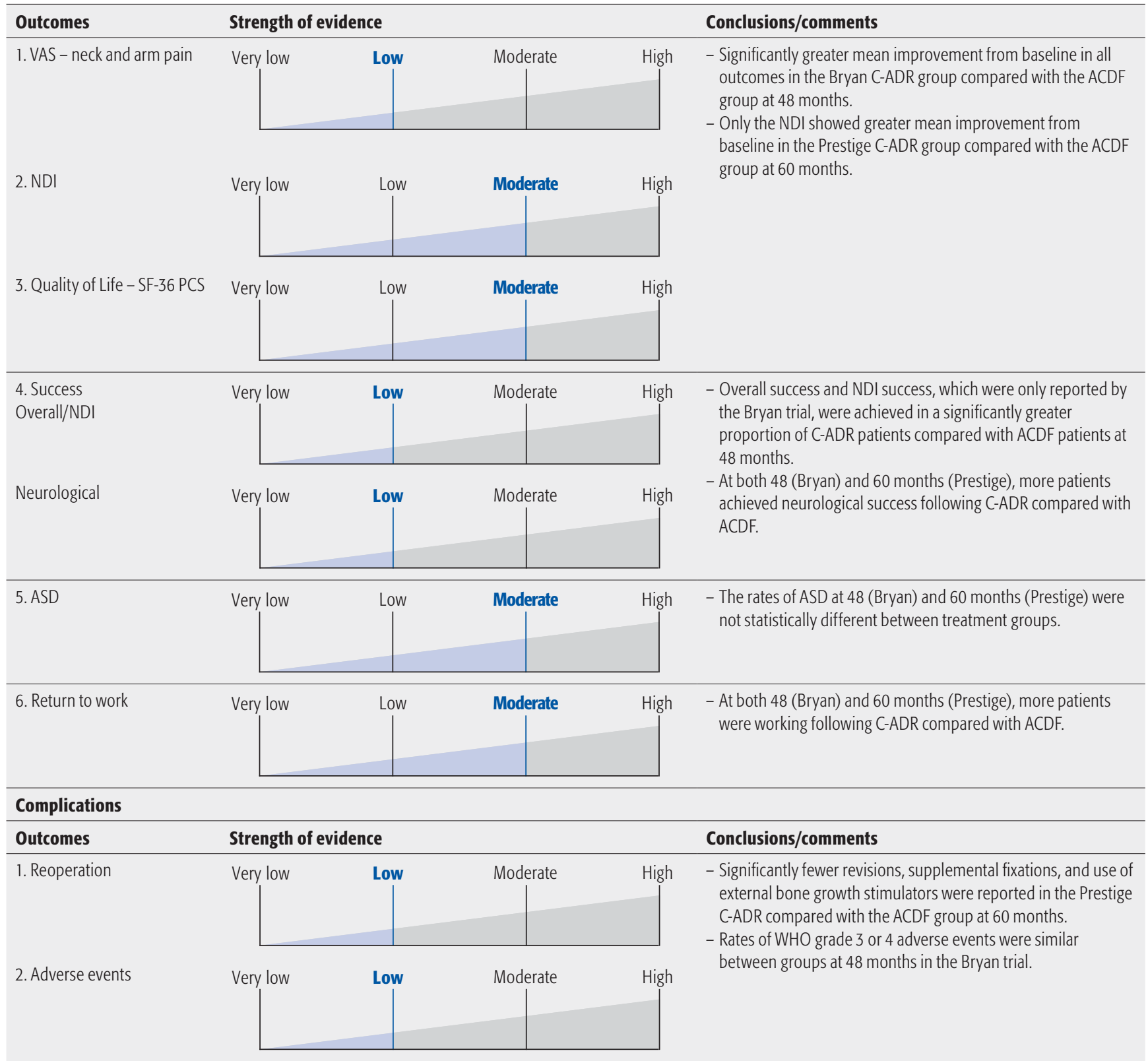




\section{SUMMARY AND CONCLUSIONS}

- Cervical arthroplasty is a viable treatment option for cervical herniated disc/spondylosis with radiculopathy. The inclusion/exclusion criteria of US FDA trials should be followed.

- C-ADR achieves neural decompression and preserves normal segmental motion at the operated level at 4 to 5 years follow-up.

- Adjacent level degeneration may be decreased with arthroplasty versus ACDF, but further study is warranted on this topic.

\section{REFERENCES}

1. Burkus JK, Haid RW Jr, Traynelis VC, et al (2010) Long-term clinical and radiographic outcomes of cervical disc replacement with the Prestige disc: results from a prospective randomized controlled clinical trial. J Neurosurg Spine; 13(3):308-318.

2. Sasso RC, Anderson PA, Riew KD, et al (2011) Results of cervical arthroplasty compared with anterior discectomy and fusion: four-year clinical outcomes in a prospective, randomized controlled trial. J Bone Joint Surg Am; 93(18):1684-1692. 